\title{
Article
}

\section{The Bio-Politics of Population Control and Sex-Selective Abortion in China and India}

\author{
Lisa Eklund, University of Lund \\ Navtej Purewal, SOAS University of London
}

\begin{abstract}
China and India, two countries with skewed sex ratios in favor of males, have introduced a wide range of policies over the past few decades to prevent couples from deselecting daughters, including criminalizing sex-selective abortion (SSA) through legal jurisdiction. This article aims to analyse how such policies are situated within the bio-politics of population control and how some of the outcomes reflect each government's inadequacy in addressing the social dynamics around abortion decision-making and the social, physical, and psychological effects on women's wellbeing in the face of criminalization of SSA. The analysis finds that overall, the criminalization of sex selection has not been successful in these two countries. Further, the broader economic, social, and cultural dynamics which produce bias against females must be a part of the strategy to combat sex selection, rather than a narrow criminalization of abortion which endangers women's access to safe reproductive health services and their social, physical, and psychological wellbeing.
\end{abstract}

Key words: abortion, bio-politics, bio-power, China, criminalization, India, sex selection 
This is the version of the article accepted for publication in Feminism \& Psychology published online by Sage Feb 122017 available at: https://doi.org/10.1177/0959353516682262

Accepted version made available via SOAS Research Online: http://eprints.soas.ac.uk/23079/ under the CC-BY-NC $\underline{\text { License }}$

\section{Introduction}

The “missing women” polemically identified in economist Amartya Sen’s (1990) seminal piece "More than 100 Million Women are Missing” attributed global trends of masculine sex ratios to daughter deselection before and after birth. China and India are two countries which show parallels with one another in terms of discrimination against females, suggesting that reproductive behavior has complex cultural and economic roots (Purewal 2010; Eklund, 2011a; 2015). Against the backdrop of a global "norm" of 105 males to 100 females, China and India show significant skews towards males, with sex ratio at birth (SRB) at 113.6 and 111 respectively (China Daily, 2016; Census of India, 2011). ${ }^{1}$ Sex ratio imbalance has been recognized by the Chinese government as a threat to development, affecting harmonious and sustainable development, and ultimately the peace and stability of the country (State Family Planning Commission, 2002). In India, alongside pursuing a Malthusian approach towards population control, the government has embarked on stigmatizing female deselection by employing the label kurimaru or “daughter-killing” in its official discourse on sex-selective abortion (SSA).

Even more significant parallels between the two countries, however, pertain to how population campaigns and government policies which aim to incentivize the birth of girl children and to deter and criminalize sex selection are shaping an emerging bio-politics of son preference and sex selection which has had disciplinary rather than transformational effects (Purewal, 2014). In both contexts, the banning of SSA has resulted in the state's use of measures of criminalization which have both attempted to ban abortions based on gender discrimination while evoking gender-laden symbols and notions (Eklund, 2011b; Purewal, 2010, 2014).

Recent moves in a number of Western contexts such as the EU, the UK, and across the United States, have shown that criminalization as an approach towards abortion is not limited to Third World or developing country contexts. For example, the 23 February 2015 UK parliamentary debate on the inclusion of SSA in the Serious Crime Bill highlighted a concerted attempt to capitalize on several years of media reportage on blurred lines between medical ethics and the supposed "social problem” of SSA (Lee, 2017; Purewal \& Eklund, forthcoming). Moreover, sex selection is being contested by both pro-choice and anti-abortion advocates; not least in relation to Asian cultural preference for sons. Thus, SSA presents a conundrum between gender discrimination against the birth of female babies and the reproductive rights of women to have access to safe abortion (Purewal \& Eklund, forthcoming). These recent shifts in rhetoric around abortion call for an analysis of how the two countries with the most skewed sex ratios have addressed the problem through various policy responses. Hence, drawing on secondary sources and census data, this article analyses the two cases of China and India; showing how each has devised policies in order to reduce sex ratio imbalance. Before analysing the two country cases, we present some theoretical concepts which guide the analysis, including various aspects of "criminalization" (Faugeron, 1995; cited in Wacquant, 2001). The results of the two country cases will be discussed in relation to recent literature on psychology and feminism with regard to SSA, before concluding with an argument highlighting the dangers of criminalization.

\section{Theoretical points of departure}


This is the version of the article accepted for publication in Feminism \& Psychology published online by Sage Feb 122017 available at: https://doi.org/10.1177/0959353516682262

Accepted version made available via SOAS Research Online: http://eprints.soas.ac.uk/23079/ under the CC-BY-NC $\underline{\text { License }}$

SSA is a practice which takes place at the individual level, but which has repercussions at the population level if it consistently and predominantly involves the abortion of female (or male) fetuses. It therefore concerns both bio-power (“women-as-species”) and bio-politics (“woman-as-body”) (Foucault, 2009). In other words, the issues of population control and skewed sex ratios against females are concerns at the population level, but policy and state approaches reflect a "disciplining of the sex ratio" through the targeting of "woman-as-body" in the criminalization of SSA. This article focuses its attention at this juncture between the bio-power and bio-politics of the sex ratio, specifically with regards to how the bio-politics of both population control and SSA have targeted women's supposed agency without adequately addressing contexts in which son preference inflects decision-making around abortion. Below follows an account of theoretical perspectives on SSA drawing on existing research from feminist, psychological, and bio-political standpoints.

\section{Sex-selective abortion: Debates about "gendercide"/"femicide"}

The concern that women and girls suffer reproductive discrimination has long been of concern and was noted as early as the eighteenth century, when British colonial administrators documented and eventually codified female infanticide in the Census of India. In the mid-1970s, the term "femicide" became a popular way to refer to the practice, drawing attention to females being "deselected" due to the sheer fact they were female and nothing more. A more recent term is "gendercide", which was coined by the feminist philosopher Mary Anne Warren (1985) in her book Gendercide: Implications for Sex Selection. Warren's book was published at a time when SSA was a less well-known practice which often took place in the second or third trimester, which points at both ethical dilemmas and concerns over the health of the mother. ${ }^{2}$ Still, Warren did not regard SSA as gendercide, although she contended it may lead to gendercide. Rather, she argued that SSA fell within the domain of reproductive choice and should be regarded a fundamental right of women. Warren later shifted her position and argued that SSA is ethically defensible only in contexts where there was no gender (son) preference (Warren, 1999).

However, Warren's later position attracted critique from feminists who argued that in practice, it would restrict the right to SSA to privileged women-mostly in the global north-and compromise the universal right to bodily autonomy, linking back to Warren's earlier arguments. Other feminist critiques of the right to abortion point to the fact that unless women have the institutional and cultural backing to form choices and act on them, granting rights to abortion carries less meaning (Smart, 1989). Feminist critiques of SSA have further framed the practice as an act of violence, by drawing attention to the rights of the female fetus, rights which are normally articulated as part of anti-abortion arguments (Goodkind, 1999). Indeed, "femicide" and "gendercide" have been conflated as part of the misleading rhetoric surrounding the debate on SSA.

\section{Disciplining sex-selective abortion}

Bio-power, as conceptualized by Michel Foucault (1998), represents the disciplinary power which nation-states employ in controlling populations through technologies of power. Defined literally as "power over bodies", bio-power is "an explosion of numerous and diverse techniques for achieving the subjugation of bodies and the control of populations" (Foucault, 1998, p. 140). Bio-politics, on 
This is the version of the article accepted for publication in Feminism \& Psychology published online by Sage Feb 122017 available at: https://doi.org/10.1177/0959353516682262

Accepted version made available via SOAS Research Online: http://eprints.soas.ac.uk/23079/ under the CC-BY-NC License

the other hand, represents the interventions and new technologies which are exerted as social and political power over life (Foucault, 1997). Few arguments from feminist and psychological points of view focus on the level of bio-politics in terms of specific interventions for disciplining SSA. However, at the level of biopower, the negative consequences of sex ratio imbalance have provided arguments of disciplining SSA through criminalization. The function of criminalizing sex selection can be viewed from different normative perspectives. Drawing inspiration from the work of sociologist Claude Faugeron (1995), we argue that the criminalization of SSA can be regarded as serving different parallel functions. In her study of prisons, Faugeron differentiates between "imprisonment of safety", "imprisonment of differentiation", and "imprisonment of authority". Analysing the criminalization of SSA using this framework allows us to identify distinct approaches; first, the "criminalization of safety" which seeks to prevent individuals from causing harm to the female fetus or "girl child", a stance which seems to unite some feminist activists with proponents of the anti-abortion movement.

Second, from the normative perspective of "criminalization of differentiation", social categories deemed undesirable—such as individuals possessing son preference-would be labelled as deviant. This perspective has constructed sex selection as a "social evil" in a criminalizing sense which has added a new layer of "bio-politicization" to abortion. As has been widely acknowledged in the field of criminology through the work of Erving Goffman (1964), stigma which is implicit in the notion of "social evil" is significant to the continuation and reproduction of social inequalities. Finally, from the normative perspective of "criminalization of authority", criminalizing sex selection would reaffirm the prerogatives and powers of the state. We agree with Mark Hatzenbuehler, Jo Phelan, and Bruce Link (2013) who critiqued the criminalization produced out of deviance and stigma in their argument that "policies and interventions must address the social factor itself, rather than the putative mechanisms that link this factor to health" (Hatzenbuehler et al., 2013, e. 1). Identifying SSA as a social evil complicates not only the "biopoliticization" of abortion, but also the use of disciplinary social control through "abnormalization" of SSA, expanding the field of bio-power through the performativity of authority of the state (Alexander, 2011).

It is here that feminist engagements with abortion and the state highlight how the criminalization approach places women and women's social, psychological, and physical wellbeing at risk. As suggested by our application of Faugeron's work, the normative "criminalization of safety" perspective posits the pregnant woman as a potential perpetrator governed by societal forces and pressures but who is also the site where such forces can culminate in the act of criminality: SSA. In India and China, the evolving bio-politics of sex ratios is intertwined with how feminists, the medical profession, and the state have all engaged with SSA. However, in what Nivedita Menon (1995) calls an "impossibility of justice", there is an implicit and reductive assumption within state laws to ban SSA that universal justice can be achieved through legal jurisdiction. This sets up a flawed and systematically perpetuating enactment of abstracted "rights" alongside their denial. According to Ratna Kapur and Brenda Crossman (1996), it is important to understand how the family, which is both a site of women's struggle and suppression, is then further encased within state's legal frameworks shaped by and reinforcing a familial and patriarchal ideology in its regulation of the normative family. Thus, while SSA has been banned and criminalized by the state, son preference remains outside of the 
This is the version of the article accepted for publication in Feminism \& Psychology published online by Sage Feb 122017 available at: https://doi.org/10.1177/0959353516682262

Accepted version made available via SOAS Research Online: http://eprints.soas.ac.uk/23079/ under the CC-BY-NC $\underline{\text { License }}$

remit of law even though it generates the reasoning behind daughter deselection.

To the contrary, as we will highlight in this article, son preference even forms the basis of many anti-sex selection campaigns in China and India. Our analysis of China and India points to the fraught relationship between abortion and sex selection in two countries where criminalization has informed policy and outcomes.

\section{The case of China}

Abortion in China was unregulated before the establishment of the People's Republic of China in 1949, but was banned during the Mao era (1949-1976), mostly due to the state's pro-natalist ambition (Cao, 2015). However, the population policy paradigm has shifted dramatically in China. The Reform era (since 1978) has been characterized by an anti-natalist policy regime. The so-called one-child policy, implemented from 1979 to 2015, when it was replaced with a two-child policy, can also be understood through the approaches suggested by our theoretical framework (above); a criminalization of safety by preventing "excess" births understood as harmful to China's development, a criminalization of differentiation by labelling couples with higher fertility preferences as “deviant”, and a criminalization of authority by transferring unprecedented powers to the state in the field of reproduction. Subsequently, in the beginning of the 1980s the abortion ban was officially lifted (Cao, 2015). Moreover, close to unrestricted availability of abortion services was key to implementing the population policy, and abortion rights were largely driven by population control concerns and not by concerns over women's reproductive and sexual rights. In fact, the women's movement in China has never prioritized access to safe abortion as a key cause of concern.

However, the population was by and large not prepared to accept the idea of having only one child, let alone the idea of not having a son (Greenhalgh \& Winckler, 2005). Consequently, the implementation of the one-child policy met with resistance, and forced abortion was used as a tool of the state to curb policy noncompliance to ensure that the "safety" issue of "excess" births was controlled (Nie, 2005). In parallel, a policy shift was in the making and by 1988, most provinces allowed rural families to have a second child if the first child was a girl, essentially sanctioning the idea that sons are necessary for the fortunes of rural families (Eklund, 2011a). Still, the urge to have a son could not fully be met by this "1.5-child policy" and the technology used to screen women for unauthorized pregnancies coupled with readily available abortion services soon offered a route for SSA. As Figure 1. illustrates, sex ratio at birth (SRB) for China as a whole was 107.6 in 1982, but increased to over 120 in 2005, before it dropped to 118 in 2010, and then 113.6 in 2015. SRB was particularly skewed in rural areas, but increased also in urban areas. By 2005, SRB in rural areas was 122.9 and 115.2 in urban areas (Eklund, 2011c). Moreover, sex selection has taken place mostly at higher parities, as evident from the fact that in 2000 SRB for the first parity was close to normal (107.1) while SRB for the second parity was 151.9. However, by 2010, SRB for the first parity had increased to 113.7, and SRB for the second parity had dropped to 130.3 (Cai, 2015: p 80). This suggests that son preference manifests itself increasingly at first parity under the "one child norm”.

Figure 1: China’s sex ratio at birth 1982-2015 
This is the version of the article accepted for publication in Feminism \& Psychology published online by Sage Feb 122017 available at: https://doi.org/10.1177/0959353516682262

Accepted version made available via SOAS Research Online: http://eprints.soas.ac.uk/23079/ under the CC-BY-NC $\underline{\text { License }}$

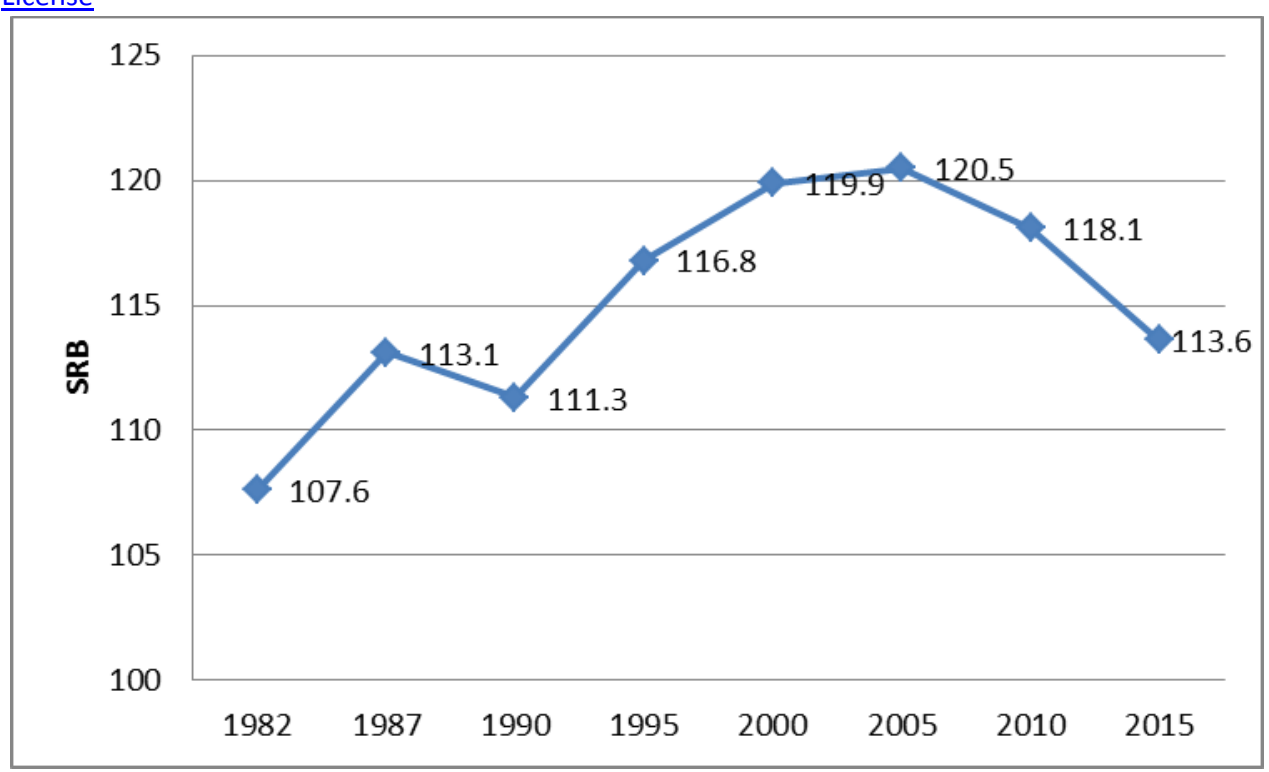

Source: China Census

Note: Table reflects the sex ratio as number of males per 100 females

Although the one-child policy alone cannot be blamed for the surge in SSA in China, it has contributed to exacerbating the problem both by setting fertility rates artificially low, and by making sex-selective technology readily available (Nie, 2010). Moreover, SSA did contribute to keeping birth rates down. The birth of an unwanted unauthorized child constituted a "lose-lose" situation for couples, who would be fined, and for family planning cadres who would fail to meet their target of no unauthorized births. Effectively, women were expected to undergo abortion in order to be "good mother subjects" in the Chinese state-building project where reducing fertility was a common good (Cao, 2015). Therefore, in some cases medical staff and family planning cadres were incentivized to turned a blind eye to SSA, capitalizing on the belief that sons are essential in order to keep the birth rates down (Eklund, 2011b). At least until the late 1990s, population control in China was characterized by the use of targets and quotas, detailing numbers and frequencies of new births, gynaecological check-ups and sterilizations; leaving a legacy of an "administrative approach" to disciplining reproductive behavior. Part and parcel of this administrative approach is forced and voluntary abortion, which has been instrumental in adhering to targets and quotas. Even today, local cadres are evaluated based on whether they can avoid unauthorized births within their jurisdiction. Failing to do so may lead to demotion or loss of position altogether. Thus, there are administrative measures built into the population control system, with repercussions beyond government officials working with population control directly, incentivizing cadres to turn a blind eye to sex selection. At least this has been the case until recently; the introduction of the 2-child-policy in 2016 reduces the "risk" of unauthorized births, and therefore removes part of such incentives.

\section{Evolution of Chinese government policy on sex selection}

Although abortion was an important measure from the point of view of criminalization of safety for population control purposes, a normative function of criminalization of safety in the context SSA (for the safety of the "girl child") emerged early on. Already in 1986, the State Commission for Family Planning and Ministry of Health jointly promulgated a regulation that prohibited pre-natal 
This is the version of the article accepted for publication in Feminism \& Psychology published online by Sage Feb 122017 available at: https://doi.org/10.1177/0959353516682262

Accepted version made available via SOAS Research Online: http://eprints.soas.ac.uk/23079/ under the CC-BY-NC License

diagnosis, except when to diagnose certain hereditary diseases. This regulation was subsequently reaffirmed in 1989, 1990, and 1993 in several circulars issued by these two authorities (Peng, 1997, cited in Nie, 2010). In 1994 the Law on Maternal and Infant Health Care criminalized not only sex identification of the fetus (unless medically motivated), but also SSA. In 2002, the Law on Population and Family Planning (henceforth, "FP Law") also stipulates that sex identification and SSA are illegal. Moreover, most provinces have (at least until 2015) in their regulations operationalizing the FP Law removed the right to have a second child in case it can be proven that the woman has undergone SSA (Eklund, 2011b). Hence, the population control policy and the policy to prevent SSA partly contradicted one another on the ways in which abortion was to be controlled (or not), contributing to a discord at the levels of both bio-politics and bio-power.

\section{Schemes and campaigns}

As shown above, the criminalization of safety to prevent excess births and the criminalization of safety to protect the "girl child" were generating conflicting messages. This may explain why criminalizing SSA proved ineffective in curbing SRB imbalance, as evident from Figure 1. Recognizing the need for a broader approach, the Chinese government launched the "Care for Girls Campaign" (henceforth, "the Campaign"), with the three-fold objective to improve the value of the girl child, promote gender equality, and normalize the imbalanced SRB by the year 2020 (CGC, 2006a). The Campaign was piloted in 11 counties in 2003 and 13 counties in 2004 (Li, 2007; Wei \& Gao, 2007), and has since been scaled up to a nationwide campaign with the interim goal of reducing SRB to 115 by 2015.

The activities of the Campaign fall into five main components: (1) undertaking awareness raising and advocacy campaigns to promote "new marriage and childbearing customs”, (2) strengthening reproductive health services and management, (3) launching beneficial socioeconomic policies for one child or two daughter families, (4) strengthening management of sex determination and SSA, and (5) improving statistical and reporting systems (CGC, 2006b). Important ingredients in the Campaign have been to foster "good citizens" (Eklund, 2011b); so, for example, daughters-only households have received awards and extra premiums (Murphy, 2003). The activities within the Campaign largely have disciplining and controlling effects, which Rachel Murphy (2014) suggests is a "care as control” policy response wherein the state ignores the institutional underpinnings of the problem. Moreover, Eklund (2011b) found that by capitalizing on stereotypical and essentialist gender norms in its information and awareness campaigns, the Campaign fosters a discourse of gender difference, partly contradicting the objective of promoting gender equality. China has been less successful in bringing about gender equality reform, as demonstrated by the recent negative trends in female labor force participation, the gender wage gap, and female political participation (Attané, 2012).

\section{Results and outcomes of policies}

By 2014, the National Health and Family Planning Commission (2014) did not foresee that the target of 115 would be met by 2015, but still SRB dropped below the target to 113.6 in 2015. It is hard to know to what extent institutions known for underpinning son preference are changing by just assessing SRB, given the controlling approach by the government which may lead to under reporting or 
This is the version of the article accepted for publication in Feminism \& Psychology published online by Sage Feb 122017 available at: https://doi.org/10.1177/0959353516682262

Accepted version made available via SOAS Research Online: http://eprints.soas.ac.uk/23079/ under the CC-BY-NC License

misreporting (Eklund, 2011a; Cao, 2015). The substantive drop to 113.6 in 2015 can possibly be attributed to SRB (just like unauthorised births) becoming an indicator against which government officials are evaluated. ${ }^{3}$ The relaxation of the one-child policy by end of 2013, which allowed couples where one of the spouses was a single child to have two children, may also have contributed to the drop in SRB. Still, it is clear that the any birth control policy interferes with the objectives and activities of the Campaign, as outlined above.

One challenge in controlling sex selection pertains to the fact that SSA requires two activities that often take place in isolation of one another. First, the sex of the fetus has to be identified, and subsequently an abortion has to be induced. These activities can take place in two different service deliver points and the medical staff performing the induced abortion may be unaware of the true motives for terminating the pregnancy. In fact, investigations suggest that SSA has frequently taken place within the health system, not the family planning system. ${ }^{4}$ In addition, a proliferation of private (and sometimes informal) practitioners makes oversight and monitoring of both sex identification and abortion services hard. Moreover, the landscape in which sex identification is taking place is shifting, with new technologies entering the market. Tests determining the sex of the fetus through a blood sample of the pregnant mother have flourished in recent years, and since 2013 the Chinese government has punished more than 11,000 cases where sexidentification tests were misused (NHFPC, 2014).

Another challenge complicating efforts to prevent SSA pertains to cross-border movement, where more affluent couples can seek sex-selective services in Hong Kong and other countries (Basten \& Verropoulou, 2013). Sending sexidentification blood tests to Hong Kong means that controlling blood tests goes beyond the jurisdiction of the Chinese government (NHFPC, 2014). Moreover, there is rampant corruption, as evident from the fact that those with financial resources and networks have even higher SRB. Data from the province of Hainan illustrate this point; in 2005, SRB was 136 in Hainan. Disaggregated further, SRB was 170 for government employees, 222 for professionals, and 250 for the heads and senior officials of government bodies, state-owned enterprises, and government organizations (He, 2006).

These challenges and developments suggest that controlling and disciplining foetal sex identification and SSA is becoming increasingly difficult, and that institutional change fostering the equal value of girls and boys is needed more than ever before. The skewed sex ratio is also one reason why China shifted to a 2-child-policy in 2016.

\section{Deepening the "bio-politicization" of SSA}

Recent developments reveal that the Chinese government is committed to further deepening the bio-politicization of SSA. According to a recent regulation jointly issued by the National Health and Family Planning Commission, the State Administration for Industry \& Commerce and the China Food and Drug Administration, couples and organisations known for undergoing or performing "medically inessential" prenatal sex determination or SSA will be fined up to 30,000 yuan (approximately US\$4,400) as of 1 May 2016 (China Daily, 2016). 
This is the version of the article accepted for publication in Feminism \& Psychology published online by Sage Feb 122017 available at: https://doi.org/10.1177/0959353516682262

Accepted version made available via SOAS Research Online: http://eprints.soas.ac.uk/23079/ under the CC-BY-NC License

The regulation further strengthens the monitoring of retail pharmacies to prevent the availability of abortion medicines and ultrasound devices for chromosome identification among unqualified institutions or individuals. Advertisers will also be punished for publishing ads for illegal prenatal sex determination and SSA services. Moreover, family planning officials' performance assessments will take prevention of illegal prenatal sex determination and sex selective abortions into account. The regulation further strengthens the horizontally exerted social and political control over SSA by welcoming the general public to inform on violations of the regulation. The general public has also been promised rewards for informing on any such violations (China Daily, 2016).

\section{The case of India}

Without the centralized authority China wields, India has not had the same ability to promote any policy as far-reaching as the one-child policy. Instead, the biopolitics of SSA in India exists against the backdrop of the colonial state's criminalization of abortion on the one hand, and on the other hand subsequent postcolonial policies to decriminalize induced abortion. Meanwhile, criminalizing sex selection has had contradictory demographic and ideological outcomes. India's abortion law, which was originally enacted in the Indian Penal Code of 1860, had until as recently as 1971 declared induced abortion illegal. As Ann Weatherall and Alison McCulloch (2017) highlight, the immorality and subsequent illegality of abortion were established by the restrictive British colonial frameworks of eugenics and pro-natalism. In postcolonial India, the women's movement and lobbyists from within the medical profession mobilized for a national campaign against unsafe abortion which resulted in the legalization of abortion in the Medical Termination of Pregnancy Act (MTP) of 1971 (Visaria, Ramachandran, Ganatra \& Kalyanwala, 2007). ${ }^{5}$ Subsequently, controlling population growth rather than improving reproductive health and wellbeing has been the priority of India's population policies. India is cited to have been the first country in the world to introduce state-led family planning initiatives in 1952, and was the first developing country to legalize abortion in 1971 (Visaria, 2007). Throughout the 1960s and 1970s India was consistently highlighted by the international community for its "population problem" with respect to poverty indicators in line with the US Agency for International Development (USAID), World Bank, and Asian Development Bank's insistence that population control would be a condition for development aid. Seen through a Malthusian lens as an impediment to economic development, India's rate of population growth featured prominently as a priority for the Indian Planning Commission which adopted a vertical approach of population control through male, and then female, sterilization. The foreign aiddriven target approach towards population control shaped the coercive and incentivization strategies of the government from the onset, resulting in a reduction in the average number of children born per woman in India from 5.2 to 2.6 between 1972 and 2008 (Registrar General of India, 2008).

Indeed, USAID had threatened in the early 1970s to withdraw funding towards development assistance until the Indian government was seen to be sufficiently targeting population growth. In attempting to show it was tackling its "population problem,” Prime Minister Indira Gandhi’s government embarked on an unpopular forced sterilization campaign during the twenty-two month "state of emergency" 
This is the version of the article accepted for publication in Feminism \& Psychology published online by Sage Feb 122017 available at: https://doi.org/10.1177/0959353516682262

Accepted version made available via SOAS Research Online: http://eprints.soas.ac.uk/23079/ under the CC-BY-NC $\underline{\text { License }}$

between 1975-1977. During this period an estimated six million men—mainly poor-were sterilized by force or coercion, showing how politically charged the population question had become in India (Kasun, 1999). One village agreed that $100 \%$ of couples would undergo sterilization, mainly vasectomy, in exchange for the installation of a tubewell (ibidem). The public verdict was that male reproductive ability was a perilous target politically, given the number of deaths and illnesses caused by the procedures, and not to mention the perceived attack on the masculinity of the masses and the poor it represented. Population campaigns subsequently turned more robustly towards women, birth control, and tubal ligation. During this time period the pattern of utilizing coercive and incentivized measures was established, signifying an administrative approach to reproductive health; an approach which would continue in subsequent decades in relation to other reproductive health issues, not least sex selection. The government-projected slogan hum do, hamaare do — "We two, our two"-was painted on freight trucks across the country, disseminating a model of the ideal family comprizing two parents and two children, in contrast to the average of 5.1 children in 1971-73. The Indian postal service issued envelopes with the message "for happy married life please be in touch with the Family Welfare Centre.” Population control and the small ideal family size had become a ubiquitous message for a range of slogans across India.

\section{Evolution of Indian government policy on sex selection}

The evidence provided by the sex ratio, as "an indicator of the politics of reproduction”, quickly revealed that population growth targets alone would not produce sustainable results (Patel, 2007, p. 32). Son preference could not be removed from the social context of reproduction and people's reproductive decision-making. While India's population growth rates had indeed dropped from 5.1 in 1971-73 to 3.2 in 1996-98, fertility rate patterns highlighted an increasingly complex picture (Registrar of India, 1998). While some couples were continuing to have large families in order to ensure the survival of male children for livelihood, security, and status concerns, others were having fewer children. However, due to the availability of pre-natal sex-identification technologies people were now able to "sex select" within this smaller number of children, resulting in an intensification of male bias (Das Gupta \& Bhat, 1997; Basu, 1999).

Figure 2. India's sex ratio: Total and 0-6 years 
This is the version of the article accepted for publication in Feminism \& Psychology published online by Sage Feb 122017 available at: https://doi.org/10.1177/0959353516682262

Accepted version made available via SOAS Research Online: http://eprints.soas.ac.uk/23079/ under the CC-BY-NC $\underline{\text { License }}$

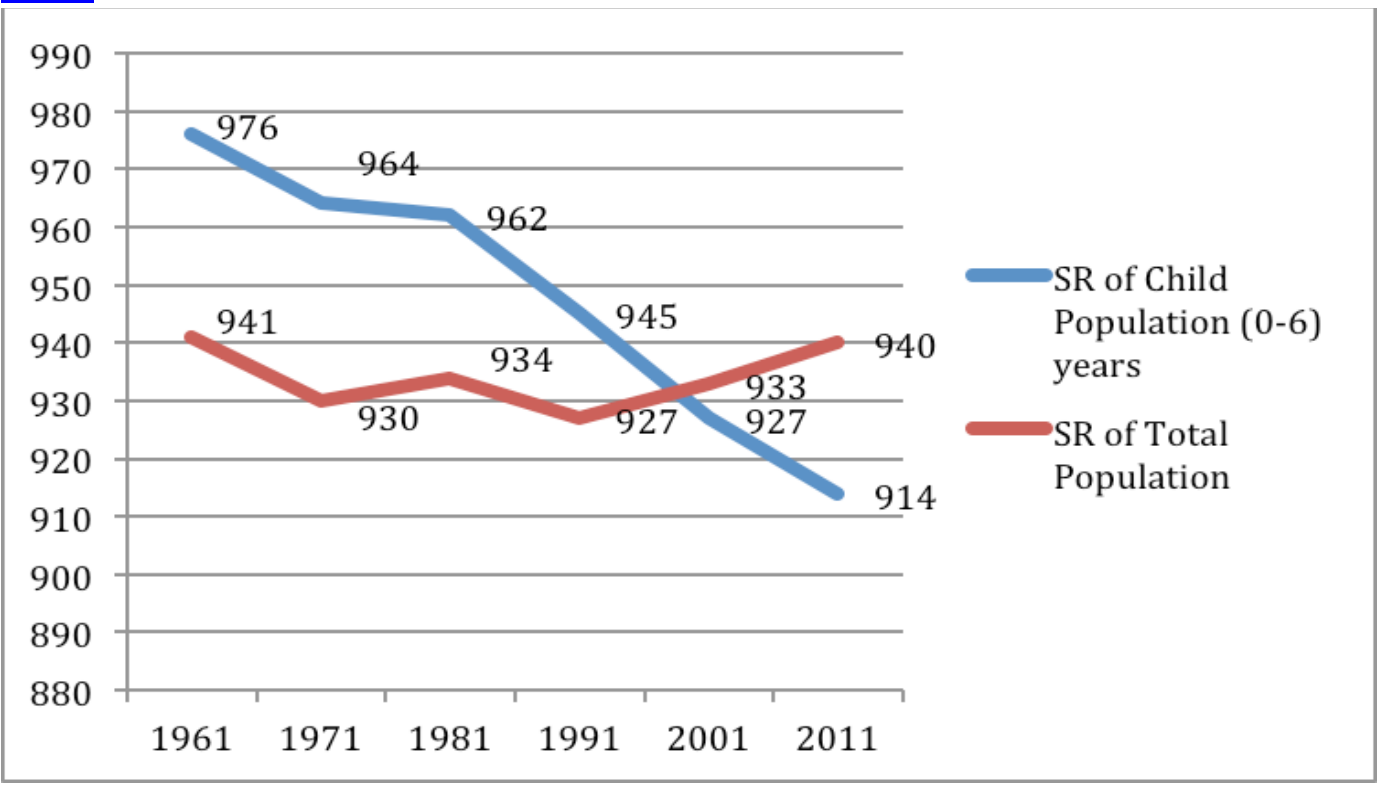

Source: Census of India from 1961 to 2011

Note: Table reflects the sex ratio as number of females per 1000 males

Figure 2 highlights the intensification of male bias most notable from the early 1980s when new reproductive technologies, such as amniocentesis and the ultrasound scan, became widely accessible. Sex selection, which had previously been termed "female infanticide" prior to the availability of reproductive technologies, was now named “female feticide” by the Indian women's movement, which mobilized against the use of reproductive technologies for prenatally deselecting females (Gandhi \& Shah, 1991). The conflation of abortion and sex selection within the term "female feticide" has had problematic implications for abortion rights, highlighting the inability of the Indian women's movement to engage with the broader issue of defending women's rights to safe abortion. The use of diagnostic methods for sex selection, including the ultrasound scan, was banned under the 1994 Pre-Natal Diagnostic Techniques (Regulation and Prevention of Misuse) (PNDT) Act, and subsequently the 2003 Pre-Conception and Pre-Natal Diagnostic Techniques (Prohibition of Sex Selection) Act; both of which were largely outcomes of the Indian women's movement's lobbying. However, as Figure 2 shows, illegalization of sex selection did not improve the downward trend in the ratio of females to males. This fact sheds light on the problematic conflation of sex selection and abortion in India (Potdar, Barua, Dalvie \& Pawar, 2015).

India's criminalization of differentiation: campaigns and schemes After the 1994 and 2003 acts, it became clear that criminalization of SSA was not improving the demographics of SRB. Therefore, a range of identifiable campaigns and schemes were introduced to address daughter discrimination and the social attitudes surrounding it. These campaigns presented a simultaneously prohibitive and seemingly preventative state narrative signifying a criminalization of safety to protect the "girl child", a criminalization of differentiation by fuelling a sense of stigma and deviance among those who sex-select, and a criminaliszation of authority to grant powers to the state-albeit much slighter and to a less explicit extent than in China. We locate three identifiable types of programmes in India within this criminalization framework which have been promoted by central, state, 
This is the version of the article accepted for publication in Feminism \& Psychology published online by Sage Feb 122017 available at: https://doi.org/10.1177/0959353516682262

Accepted version made available via SOAS Research Online: http://eprints.soas.ac.uk/23079/ under the CC-BY-NC License

and local/union territory governments: (1) sensitizing schemes, (2) incentivizing schemes, and (3) deterrence schemes.

Sensitization schemes have been an ever-present feature of public social awareness in India since the Decade of the Girl Child (1990-2000). In 2009, the $24^{\text {th }}$ of January was declared to be National Girl Child Day, and has since been marked each year at "anti-female feticide" events. As part of these events, students at schools, colleges, and universities produce posters, make presentations, and organize pledges to not undergo or partake in the act of SSA (Purewal, 2014). The earlier mentioned hum do, humaare do campaign began to be replaced by the "Save the Girl Child" campaign, demonstrating the changing official discourse and imperatives of the bio-politics of sex selection. The "Save the Girl Child" campaign used images and slogans projecting the notion of protecting the girl child as a socially noble and charitable act, in a similar vein as the "Care for Girls Campaign” in China. These awareness programmes have remained superficial in neglecting to address protocols of father to son inheritance, social relations, reciprocity, and exogamous marriage. Thus, the patriarchal underpinnings of son preference-for instance, viewing women's existence primarily in relation to the male-headed household-have not been challenged. Indeed, in his August 2015 address to the nation Prime Minister Narendra Modi of the ruling right-wing Hindutva BJP party made a statement on the theme Beti Bachao- "Save the Daughter” (National Informatics Centre, 2015). Such an approach is emblematic of this type of sensitization campaign in pronouncing the protection of the girl child, while remaining silent on the structural, cultural, and economic dimensions of son preference which lead to pre- and post-natal discrimination.

Incentives designed to encourage couples to continue daughter pregnancies have taken the form of financial schemes, facilitated by the banking sector, to give support to the parents of female children in lieu of the burden which is associated with having daughters. Across Indian states and union territories such as Delhi and Chandigarh ladli or "doted-upon daughter" schemes have been introduced, wherein the government makes contributions at milestone points in a girls' life until she reaches the age of eighteen, when she can access the lump sum. In a similar way to the awareness-raizing campaigns, incentive schemes have avoided confronting the cultural backdrop of asymmetrical marriage dynamics between the girl's side (bride) and the boy's side (groom), and the dowry customs which burden the parents of girls. Instead, such schemes have perpetuated the notion of daughters as financial burdens by "selling" the idea of not committing female feticide as an opportunity to take advantage of such schemes to offset the costs incurred by having a daughter (Purewal, 2010). However, in societies where giving birth to sons awards women status, the availability of sex-selective technologies "allows women to gain control over what has earlier been seen as an immutable process of birth and kinship-building” (Mallik, 2010, p. 189). Similarly, the family context of women's obligations and aspirations to reproduce a certain ideal patriarchal family is implicit in reproductive decision-making, thus further relegating such incentive schemes to the "massifying" functions of the public SSA discursive sphere (Unnithan-Kumar, 2010).

The criminalization of sex selection in India is centred on activities best described as deterrence as part of the "criminalization of differentiation". By representing the 
This is the version of the article accepted for publication in Feminism \& Psychology published online by Sage Feb 122017 available at: https://doi.org/10.1177/0959353516682262

Accepted version made available via SOAS Research Online: http://eprints.soas.ac.uk/23079/ under the CC-BY-NC $\underline{\text { License }}$

illegal and criminalized status of SSA, deterring campaigns wield the tools of state surveillance and punishment without the follow-up of prosecution. Surveillance through records managed by information technologies, bureaucratic systems, and the threat of "naming and shaming" have all been key to the government's approach, which has neither been heavy-handed in policing medical and reproductive health services nor overtly interventionist in identifying and convicting perpetrators.

\section{Results and outcomes of policies}

In India, sex selection and population policy have a combined history in which Malthusian-inspired coercive techniques of population control have contributed to the “disciplinary blockade” around sex selection (Purewal, 2014). While medical, social, and feminist activists initially viewed the 1994 and 2003 legislation as victories, the fact that the sex ratio continued to decline while few cases emerged or resulted in legal action showed how criminalization merely led to the emergence of an official anti-female feticide discourse in India. India's evolving bio-politics of SSA has been driven by a culture of patriarchy, son preference, and a technological route through abortion. As a result, it has enabled a bio-politics of sex-selective misogyny within which women are directly or indirectly making choices to selectively abort females, as is evident in the 0-6 age sex ratio data. Such choices are due in part to a societal context in which daughters are viewed as weakening to a woman's status and security. The pressure upon women to produce sons is an integral part of reproductive decision-making in which women negotiate and bargain with patriarchy about their fertility under the radar of the rhetorical bio-power discourse on criminalized SSA.

\section{A missing facet: Psychological dimensions of son preference and sex-selective abortion}

As the two country cases have illustrated, the psychological facets of SSA have, to date, not been a point of departure for policy responses to SSA in China and India. Rather, they have been largely overlooked and underexplored. However, even though policy makers seem to have been unconcerned about the psychological dimensions of SSA, demographers, social scientists, and feminist scholars have commented extensively on how son preference inflects how abortion is perceived and accessed in contexts where daughters are viewed as detrimental to familybuilding strategies. Within these studies, there are several levels of inquiry which illuminate the need for further attention to the psychological dimensions of SSA.

\section{SSA as violence}

Several studies draw attention towards how reproductive coercion relates to intimate partner violence (Miller, Jordan, Levenson \& Silverman, 2010; Thiel de Bocanegra, Rostovtseva, Khera \& Godhwani, 2010). Such studies not only show how SSA can be related to intimate partner violence, but also how extended family members contribute to reproductive coercion through silencing and refraining from protecting women who are subjected to coercion (Puri et al., 2011). Moreover, several studies have pointed to the psychological and physical consequences for both women and their daughters if an unwanted daughter is born (Arnold, Kishor \& Roy, 2002). Martin Rew, Geetanjali Gangoli, and Aisha Gill (2013) have 
This is the version of the article accepted for publication in Feminism \& Psychology published online by Sage Feb 122017 available at: https://doi.org/10.1177/0959353516682262

Accepted version made available via SOAS Research Online: http://eprints.soas.ac.uk/23079/ under the CC-BY-NC License

documented increased violence against such women, while others have observed divorce as a result of women shouldering the blame and burden for giving birth to daughters (Bélanger, 2003). SSA therefore could be understood, in this light, as a "preventative measure" taken by women as an alternative to female infanticide, as a means of saving a female child from a life of discrimination, or as a pre-empted avoidance of dowry obligations (Santhya \& Verma, 2004). The normative function of "criminalization of safety" thus departs from a very limited definition and scope of safety, safeguarding the female fetus, while disregarding the safety of the girl child and the mother. Indeed, the pressures on women to "produce" sons and deselect daughters provide a backdrop to experiences of physical or psychological abuse or violence against women in the domestic sphere, as noted in studies carried out in India (Raj et al., 2011; Rew et al., 2013).

\section{SSA and shame}

Criminalization also potentially adds psychological stress to the mother who, when undergoing SSA, "violates" the "safety” of the female fetus. Hence, as Puri et al. (2011) found, women facing psychological pressure to undergo a SSA confront a complex set of concerns and considerations which are all potentially detrimental. For instance, a woman who, does not carry out SSA and proceeds with a pregnancy and delivery of a daughter may suffer psychologically, while another woman undergoing SSA may experience adverse psychological effects such as shame, guilt, and regret.While criminalization of safety generates a sense of guilt, criminalization of differentiation generates shame. Yet, giving birth to girls only can also generate shame in relation to the family and wider community. In a recent study of pregnant women attending an antenatal clinic in a government hospital in Jamnagar (in Gujarat, India) 20.5 percent women of the sample admitted that they would undergo SSA if the diagnostic test identified a female fetus (Vadera, Joshi, Unadakat, B. Yadav \& S. Yadav, 2007). Neelima Bhagat, Anyana Ray Laskar and Nandini Sharma's (2012) study goes further in arguing that the higher propensity towards son preference in a community, the higher the chances of female SSA being practiced:

People talk about you when you don't have a son. In order to shut their mouthshaving a son is a must. Also, a brother is required for a sister. [Adolescent group] (Bhagatet al., 2012, p. 96; emphasis in original)

\section{SSA, “choice” and technology}

Some of the literature challenges the perception of reproductive technologies as furthering women's reproductive choice, questioning the extent to which SSA enables more choice for women who would otherwise be victimized for giving birth to female babies (Petchesky, 1987; Purewal, 2010). The pressures placed on women by family and wider society problematize the notion of SSA as an option or "choice" for women to either enter a "bargain with patriarchy" or to be subjected to coercive and structural forms of violence controlling women's fertility and autonomy (Kandiyoti, 1988). Further, having the "choice” to sex-selectively abort is not a choice which necessarily increases women's reproductive "rights" or liberties, but exemplifies how reproductive technologies undermine women's reproductive autonomy in the context of son preference. This, in our view, 
This is the version of the article accepted for publication in Feminism \& Psychology published online by Sage Feb 122017 available at: https://doi.org/10.1177/0959353516682262

Accepted version made available via SOAS Research Online: http://eprints.soas.ac.uk/23079/ under the CC-BY-NC License

represents a silencing of the "missing" subaltern voices of pregnant women through the "epistemic violence" of hegemonic son preference ideology and discourse (Spivak, 1988). As Sunita Puri, Vincanne Adams, Susan Ivey, and Robert Nachtigall (2011) state, technologies enabling sex-selection also blur the psychological pressure to undergo SSA with available medical procedures and technologies in the context of son preference:

Far from being value neutral, medical technologies enabling sex selection mediate and modify pre-existing societal preferences for male children, facilitating a shift from female infanticide to more medically sanitized, legal ways of ensuring the birth of a son. (Puriet al., 2011, p. 1175)

The psychological impacts of the pressures on women to adhere to the expectations of son preference in societies where it is latent or dominant, such as in China and India-i.e. to "produce" sons to be accepted socially_are of concern in understanding how the practice and criminalization of SSA will bear upon women. Our point here is that the biological and social dimensions come together in shaping women's psychological experiences of SSA. This suggests that potentially psychologically traumatic dangers of undergoing SSA cannot be alleviated by advancements in bio-technology, despite the enablement of sex identification at a much earlier stage in the gestation cycle, including through blood testing of the mother (Bianchi, 2006).

Resistance to systematic male/patriarchal proprietary control over women's sexuality and reproduction has been of concern for radical feminists in articulating violences that are exerted in order to curb women's autonomy (Wilson \& Daly, 1992). While the right to safe abortion services circulates as the dominant message within the global feminist movement within regard to reproductive health, the feminist movements in China and India have not focused on the right to safe abortion. Rather, in particular in the Indian context, framing SSA as "female feticide" or "femicide” advances arguments for limiting women's right to safe abortion. Moreover, son preference and SSA pose further questions to women both in terms of control (women's control over their bodies versus coercive control) and "choice" (whether daughter deselection is a form of violence or an act of "choice”). The family as a site for structural violence requires examination for its systematic relevance in terms of how women are situated and situate themselves within economic and social structures. "Good daughters” waive inheritance rights, despite women's legal rights to inherit in India, in fear of being ostracized from their families or labelled "selfish sisters" (Kelkar, 1992, p. 118). The psychological and social dimensions of women's positionality within the family in terms of productive and reproductive roles are systematically gendered. It is the social context (often framed by hegemonic son preference ideology) within which SSA's psychological impacts need to be better understood. This suggests that while the psychological (and physiological) costs of undergoing an abortion may have been more broadly reduced by reproductive technologies, the social context and social costs specifically in terms of SSA require another set of questions in assessing women's agency in decision-making, their understandings and articulations of "choice", and how these shape the bio-politics of SSA and son preference.

\section{Concluding remarks}


This is the version of the article accepted for publication in Feminism \& Psychology published online by Sage Feb 122017 available at: https://doi.org/10.1177/0959353516682262

Accepted version made available via SOAS Research Online: http://eprints.soas.ac.uk/23079/ under the CC-BY-NC $\underline{\text { License }}$

In this article we have described government approaches to sex selection in China and India, and analysed how these exhibit coercion and criminalization which, in turn, produce disciplinary environments that fail to address the underlying causes of male bias that generate skewed sex ratios against females. Both countries have long-standing track records of policy approaches towards sex selection. However, neither India nor China have shown efforts to consider women's wellbeing within the prevention of daughter deselection or in the support of women from within the household and family level where the pressures around reproduction take place. While medical access to abortion and legal dimensions of SSA have prevailed, broader concerns with son preference and women's decision-making, "rights" and wellbeing have been left out of formal responses to SSA in both contexts. Despite representing different types of political regimes, China and India reveal remarkable similarities in key challenges, approaches, and population policy outcomes, particularly in terms of "criminalization of authority”, where banning SSA has contributed to the reasserting the prerogatives and powers of the state. Each country has used distinctive approaches of criminalization of SSA within their broader population control strategies; China has adopted a more interventionist and centralized population policy, while India has had a less interventionist, though discursively criminalizing, approach. Each context represents a particular biopolitics of population control which has shaped how each government has addressed sex selection.

The bifurcation of official and unofficial discourses explains how and why SSA has continued despite the criminalization of sex selection. This official discourse on sex selection has thus served the vertically-directed policy function to "massify" and criminalize SSA, while the practice of SSA has largely continued through informal unregulated means. The decadal patterns of the skewed sex ratio highlight this most starkly. In India, the outcome of this has been the emergence of an "anti-female feticide" discourse accompanied by an administrative approach of quotas, targets, and surveillance of records. The threat of being "named and shamed" is a function of criminalization of differentiation which, while looming large, shows virtually no cases of those breaching the law ever brought forward formally. In China, the outcomes of the administrative approach are similar, but the function of criminalization of authority is more prominent, and has been intensified through further bio-politization of SSA. In both cases feminist and psychological aspects of SSA are absent from policy discourse and practices. It is apparent that criminalization of sex selection exists alongside broader population policies and programmes within the bio-politics of SSA, shedding light on the contradictions which are inherent in population control, women's "rights", and criminalizing SSA.

The economic, social, and cultural dynamics which produce bias against females must be a part of the strategy to combat sex selection, rather than a narrow criminalization of abortion which endangers women's access to safe reproductive health services (Ganatra, 2008). As this article has demonstrated, the psychological impacts of SSA are manifold, not least in terms of the internalization of epistemic violence by women, men, and extended families; but also more broadly the absorption of this violence by societies in India and China which have been subject to disciplinary state population control and subsequently targeted programmes to "save" or "care for" girl children. Criminalization with its various functions, be it 
This is the version of the article accepted for publication in Feminism \& Psychology published online by Sage Feb 122017 available at: https://doi.org/10.1177/0959353516682262

Accepted version made available via SOAS Research Online: http://eprints.soas.ac.uk/23079/ under the CC-BY-NC License

for safety ("protecting” the girl child), differentiation (instigating stigma and deviance), or authority (to reaffirm the powers of the state) all fail to take into account the social, physical, and psychological wellbeing of women.

This article has presented the dangerous scenario that criminalization has posed in the cases of India and China where the governments have approached SSA without addressing the social backdrop in which women require support. The psychological consequences for women refuting SSA are not well understood or documented, pointing to an important area for future research. We argue that policies need to more concertedly address the socio-economic gender dynamics underpinning son preference, rather than looking to India and China to replicate draconian measures of coercion and criminalization. In order for those policies to be effective, more knowledge is needed with regards to not only how SSA impacts on society but also how SSA and the criminalization of SSA effect women's social, physical, and psychological wellbeing. 
This is the version of the article accepted for publication in Feminism \& Psychology published online by Sage Feb 122017 available at: https://doi.org/10.1177/0959353516682262

Accepted version made available via SOAS Research Online: http://eprints.soas.ac.uk/23079/ under the CC-BY-NC $\underline{\text { License }}$

\section{References}

Alexander, J.C. (2011). Performance and Power. Hoboken, NJ: John Wiley \& Sons.

Arnold, F., Kishor, S., \& Roy, T.K. (2002). Sex-Selective Abortions in India.

Population and Development Review, 28, 759-785.

Attané, I. (2012). Being a Woman in China Today: A Demography of Gender. China Perspectives, 4, 5-15.

Basten, S. \& Verropoulou, G. (2013). Maternity Migration and the Increased Sex Ratio at Birth in Hong Kong SAR. Population Studies, 67, 323-334.

Basu, A. (1999). Fertility Decline and Increasing Gender Imbalance in India, Including a Possible South Indian Turnaround. Development and Change, 30, 237263.

Bélanger, D. (2002). Son Preference in a Rural Village in North Vietnam. Studies in Family Planning, 33, 321-334.

Bhagat, N., Laskar, A.R., \& Sharma, N. (2012). Women’s Perception About Sex Selection in an Urban Slum in Delhi. Journal of Reproductive and Infant Psychology, 30, 92-104.

Bianchi, D.W. (2006). At-Home Fetal DNA Gender Testing. Obstet Gynecol., 107, 216-218.

Cai, Y. (2015). China’s demographic challenges: gender imbalance, in deLisle, J. and Goldstein, A. (Eds). China's Challenges. University of Pennsylvania Press. Pp 60-83.

Cao, W. (2015). Exploring “Glorious Motherhood” in Chinese Abortion Law and Policy. Feminist Legal Studies, 23, 295-318.

China Daily (2016). Revised regulation tough on sex-selective abortions, China Daily 2016-04-30. Retrieved from http://africa.chinadaily.com.cn/china/201604/30/content_24983614.htm

CGC (2006a). Care for Girls Campaign: A Resource of Knowledge. The office of the Leading Group of the National Care for Girls Campaign, China Population House. [In Chinese]

CGC (2006b). Operational Guidelines for the Care for Girls Campaign. Beijing: China Population House. [In Chinese]

Das Gupta, M., \& Mari Bhat, P.N. (1997). Fertility Decline and Increased Manifestation of Sex Bias in India. Population Studies, 51, 307-15.

Eklund, L. (2011a). Rethinking son preference-Gender, population dynamics and social change in the People's Republic of China, Lund University dissertations in sociology, Vol. 96. 
This is the version of the article accepted for publication in Feminism \& Psychology published online by Sage Feb 122017 available at: https://doi.org/10.1177/0959353516682262

Accepted version made available via SOAS Research Online: http://eprints.soas.ac.uk/23079/ under the CC-BY-NC License

Eklund, L. (2011b). “Good Citizens Prefer Daughters”: Gender, Rurality and the Care for Girls Campaign. In T. Jacka \& S. Sargeson (Eds.). Women, Gender and Development in Rural China (124-142). London: Edward Elgar.

Eklund, L. (2011c). Modeling Prenatal Son Preference: Some New Perspectives from China. Population Review, 50(2):47-66.

Eklund, L. (2015). Son Preference Reconfigured? A Qualitative Study of Migration and Social Change in Four Chinese Villages. The China Quarterly, 224, 1026-1047.

Faugeron, C. (1995). La Dérive Pénale. Esprit, 215, 132-144. [in French]

Foucault, M. (1997). Society Must Be Defended: Lectures at the Collège de France, 1975-1976. New York, NY: St. Martin’s Press.

Foucault, M. (1998). The History of Sexuality Volume 1: The Will to Knowledge.(R. Hurley, trans.). London: Penguin. (Original work published in 1976).

Foucault, M. (2009). 25 January 1978. In M.S. Foucault, F. Ewald \& A. Fontana (Eds.). Security, Territory, and Population: Lectures at the Collège de France 19771978. (G. Burchell, trans.). New York, NY: Palgrave-Macmillan.

Ganatra, B. (2008). Maintaining Access to Safe Abortion and Reducing Sex Ratio Imbalances in Asia. Reproductive Health Matters, 16, 90-98.

Gandhi, N. \& Shah, N. (1991). The Issues at Stake: Theory and Practice in the Contemporary Women's Movement in India. New Delhi: Kali for Women.

Goffman, E. (1964). The Neglected Situation. American Anthropologist, 66, 133136.

Goodkind, D. (1999). Should Prenatal Sex Selection be Restricted? Ethical Questions and Their Implications for Research and Policy. Population Studies, 53, 49-61.

Government of India (2011). Provisional Population- Census.

http://www.censusindia.gov.in

Greenhalgh, S. \& Winckler, E. (2005). Governing China's Population: From Leninist to Neoliberal Biopolitics. Stanford, CA: Stanford University Press.

Hatzenbuehler, M., Phelean, J.C., \& Link, B.G. (2013). Stigma as a Fundamental Cause of Population Health Inequalities. American Journal of Public Health, 103, 813-821.

He, G.L. (2006). The Corrupt Background to China’s Sex-Selective Fertility. Retrieved from http://archives.cnd.org/HXWK/author/HE-Qinglian/kd0607234.gb.html [in Chinese]

Hesketh T. (2011). Selecting Sex: The Effect of Preferring Sons. Early Human Development, 87, 759-761. 
This is the version of the article accepted for publication in Feminism \& Psychology published online by Sage Feb 122017 available at: https://doi.org/10.1177/0959353516682262

Accepted version made available via SOAS Research Online: http://eprints.soas.ac.uk/23079/ under the CC-BY-NC License

Kandiyoti, D. (1988). Bargaining with Patriarchy. Gender and Society, 2, 274-290.

Kapur, R. \& Crossman, B. (1996). Subversive Sites: Feminist Engagement with Law in India. New Delhi: Sage.

Kasun, J.R. (1999). The War Against Population: The Economics and Ideology of Population Control. San Francisco, CA: Ignatious Press.

Kelkar, G. (1992). Women and Structural Violence in India. In J. Radford \& D.E.H. Russell (Eds.). Femicide: The Politics of Woman Killing. New York, NY: Twayne Publishers.

Lee, E. (2017). Constructing Abortion as a Social Problem: "Sex Selection” and the British Abortion Debate. Feminism and Psychology, 27.

Li, S. (2007). Imbalanced Sex Ratio at Birth and Comprehensive Intervention in China. 4th Asia Pacific Conference on Reproductive and Sexual Health and Rights. Hyderabad, India. Online article retrieved from http://www.unfpa.org/gender/docs/studies/china.pdf

Macklin, R. (1999). Against Relativism: Cultural Diversity and the Search for Ethical Universals in Medicine. New York, NY: Oxford University Press.

Mallik, R. (2002). Sex Selection: A Gender-Based Preference for a Pregnancy. Reproductive Health Matters, 10, 189-90.

Menon, N. (1995). The Impossibility of "Justice": Female Foeticide and Feminist Discourse on Abortion. Contributions to Indian Sociology, 1-2, 369-392.

Miller, E., Jordan, B., Levenson, R., \& Silverman, J.G. (2010). Reproductive Coercion: Connecting the Dots Between Partner Violence and Unintended Pregnancy. Contraception, 81 (6), 457-459.

Murphy, R. (2003). Fertility and Distorted Sex Ratios in a Rural Chinese County: Culture, State, and Policy. Population and Development Review, 29, 595-626.

Murphy, R. (2014). Sex Ratio Imbalances and China's Care for Girls Programme: A Case Study of a Social Problem. The China Quarterly, 219, 781-807.

National Health and Family Planning Commission (2014). NHFPC Holds National Conference on Sex Ratio at Birth, 30 July 2014. Retrieved from http://www.chinadaily.com.cn/m/chinahealth/2014-07/30/content_18217722.htm

National Bureau of Statistics of China (2011). Social, Science and Technology Statistics, Tabulation on the 2010 Population Census of the People's Republic of China. Beijing: China Statistics Press.

National Informatics Centre (2015). Mann ki Baat - Part 24 [audio recording in Hindi]. Accessed 16-10-2015 via http://pmindiawebcast.nic.in 
This is the version of the article accepted for publication in Feminism \& Psychology published online by Sage Feb 122017 available at: https://doi.org/10.1177/0959353516682262

Accepted version made available via SOAS Research Online: http://eprints.soas.ac.uk/23079/ under the CC-BY-NC License

Nie, J.B. (2005). Behind the Silence: Chinese Voices on Abortion. Lanham, ML: Rowman and Littlefield.

Nie, J.B. (2010). Limits of State Intervention in Sex-selective Abortion: The Case of China. Culture, Health \& Sexuality, 12, 205-219.

Patel, T. (2007). Introduction. In T. Patel (Ed.) Sex-Selective Abortion in India: Gender, Society and New Reproductive Technologies (27-60). New Delhi: Sage Publications.

Petchesky, R.P. (1987). Foetal Images: The Power of Visual Culture in the Politics of Reproduction. In M. Stanworth (Ed.). Reproductive Technologies: Gender, Motherhood and Medicine (57-80). London: Polity.

Potdar, P., Barua, A., Dalvie, S., \& Pawar, A. (2015). "If a woman has even one daughter, I refuse to perform the abortion”: Sex Determination and Safe Abortion in India. Reproductive Health Matters, 23, 114-125.

Purewal, N. (2010). Son Preference: Sex Selection, Gender and Culture in South Asia. Oxford: Berg.

Purewal, N. (2014). Disciplining the Sex Ratio: Exploring the Governmentality of Female Feticide in India. Identities: Global Studies in Culture and Power, 21, 466480.

Purewal, N. \& Eklund, L. (forthcoming). “Gendercide”, Abortion Policy, and the Disciplining of Prenatal Sex-Selection in Neoliberal Europe. Global Public Health.

Puri, S., Adams, V., Ivey, S., \& Nachtigall, R. D. (2011). "There is such a thing as too many daughters, but not too many sons”: A Qualitative Study of Son Preference and Fetal Sex Selection Among Indian Immigrants in the United States. Social Science \& Medicine, 72, 1169-1176.

Radford, J. (1992). Introduction. In J. Radford \& D.E.H. Russell (Eds.). Femicide: The Politics of Woman Killing (3-12). New York, NY: Twayne Publishers.

Raj, A., Sabarwal, S., Decker, M. R., Nair, S., Jethva, M., Krishnan, S., \& Silverman, J. G. (2011). Abuse From In-Laws During Pregnancy and Post-Partum: Qualitative and Quantitative Findings from Low-Income Mothers of Infants in Mumbai, India. Maternal and Child Health Journal, 15, 700-712.

Registrar General of India (1998). Sample Registration System.

Registrar General of India (2008). Sample Registration System.

Rew, M., Gangoli, G., \& Gill, A. K. (2013). Violence Between Female In-Laws in India. Journal of International Women's Studies, 14, 147-160.

Sen, A. (1990, 20 December). More than 100 Million Women are Missing. New York 
This is the version of the article accepted for publication in Feminism \& Psychology published online by Sage Feb 122017 available at: https://doi.org/10.1177/0959353516682262

Accepted version made available via SOAS Research Online: http://eprints.soas.ac.uk/23079/ under the CC-BY-NC $\underline{\text { License }}$

Review, 61-66.

State Family Planning Commission (2002). Opinions on Issues of Managing Increased Sex Ratio at Birth Imbalance. State Family Planning Commission. [In Chinese]

Smart, C. (1989). Feminism and the Power of Law. London: Routledge.

Thiel de Bocanegra, H., Rostovtseva, D., Khera, S., \& Godhwani, N. (2010). Experiences with Birth Control Sabotage and Forced Sex of Women in Domestic Violence Shelters. Violence Against Women, 16, 601-612.

Unnithan-Kumar, M. (2010). Female Sex Selective Abortion - Beyond "Culture": Family-Making and Gender Inequality in a Globalising India. Culture, Health and Sexuality, 12, 153-166.

Vadera B. N., Joshi, U. K., Unadakat, S. V., Yadav, B. S., \& Yadav, S. (2007). Study on Knowledge, Attitude and Practices Regarding Gender Preference and Female Feticide Among Pregnant Women. Indian Journal of Community Medicine 32, 300301. Available from: http://www.ijcm.org.in/text.asp?2007/32/4/300/37703

Visaria, L. (2007). Sex-Selective Abortion in Gujarat and Haryana: Some Empirical Evidence. In L. Visaria \& V. Ramachandran (Eds.). Abortion in India: Ground Realities (133-167). New Delhi: Routledge.

Visaria, L., Ramachandran, V., Ganatra, B., \& Kalyanwala, S. (2007). Abortion Use and Practice: Evidence, Challenges and Emerging Issues. In L. Visaria \& V. Ramachandran (Eds.). Abortion in India: Ground Realities (1-27). New Delhi: Routledge.

Wacquant, L. (2001). The Penalisation of Poverty and the Rise of Neo-Liberalism. European Journal on Criminal Policy and Research, 9, 401-412.

Warren, M.A. (1985). Gendercide: The Implications of Sex Selection. Totowa, NJ: Rowman \& Allanheld.

Warren, M.A. (1999). Sex Selection: Individual Choice or Cultural Coercion? In H. Kuhse \& P. Singer (Eds.). Bioethics: An Anthology (137-142). Oxford: Blackwell.

Weatherall, A. and A. McCulloch (2017).The Fragility of De Facto Abortion on Demand in Aotearoa. Feminism and Psychology. 27.

Wei, X. \& Gao, L. (2007). Analysis and Recommendations on the Policies of the Care for Girls Campaign: A Gender Perspective. Sixiang Zhanxian, 33, 80-85. [In Chinese]

Wilson, M. \& Daly, M. (1992). Til Death Do Us Part. In J. Radford \& D.E.H. Russell (Eds.). Femicide: The Politics of Woman Killing (83-98). New York, NY: Twayne Publishers. 
This is the version of the article accepted for publication in Feminism \& Psychology published online by Sage Feb 122017 available at: https://doi.org/10.1177/0959353516682262

Accepted version made available via SOAS Research Online: http://eprints.soas.ac.uk/23079/ under the CC-BY-NC License

${ }^{1}$ The sex ratio is reflected in demographic terms differently in India and China. In India the sex ratio is represented as the number of females to every 1000 males. In China the sex ratio is represented as the number of males to every 100 females. Thus, a sex ratio showing a continuing skew against females would be declining in India, while the same pattern would be expressed as increasing in China.

${ }^{2}$ Other means of sex selection, such as sperm-sorting and pre-implantation sex selection of embryos were only lofty aspirations, and in fact many commentators foresaw that such technology would not be available in the near future. These new forms of technologies offer new alternatives of sex selection beyond the abortion question.

${ }^{3}$ There is no evidence for when exactly SRB was added to the cadre evaluation system, but it is likely it was introduced as part of the implementation of the $12^{\text {th }}$ 5-year-plan (2011-2015), at least in some parts of the country. As of 2016, it is a national-wide component of the cadre evaluation system (China Daily, 2016).

${ }^{4}$ It should be noted that as of March 2013, the Ministry of Health and the National Population and Family Planning Commission merged into one ministry, the National Health and Family Planning Commission.

${ }^{5}$ The MTP Act of 1971 made abortion legal up to 20 weeks of gestation but not after. An amendment, which is pending, was proposed in 2014 to extend this to 24 weeks. 